\title{
Kemoterapi Tedavisi Alan Çocukların Bakım Vericilerinin Tedaviye Bağlı Komplikasyonlara Yönelik Eğitim Alma ve Uygulama Özellikleri $\infty$
}

\author{
Sibel KÜÇÜK ${ }^{1}$,Zeynep UZUN² ${ }^{2}$, Selda IŞIK EYYUPLU
}

\section{öz}

Amaç: Araştırma kemoterapi tedavisi alan çocukların bakım vericilerinin tedaviye bağlı komplikasyonlara yönelik eğitim alma ve uygulama özelliklerinin incelenmesi amacıyla tanımlayıcı kesitsel tipte yapılmıştır.

Gereç ve Yöntem: Kemoterapi tedavisi alan 200 çocuğun bakım vericisi araştırmanın örneklemini oluşturmuştur. Veriler 67 soruluk veri formu ile toplanmıştır. Değerlendirmede sayı, yüzde, Ki-kare testleri kullanılmıştır.

Bulgular: Bakım vericilerin \%42.4'ü özel bir eğitim hemşiresinden eğitim almak istediğini belirtmiştir. Eğitimin verilme zamanı ile ağız bakımında kullanılan malzeme, yediklerini not etme ve bildirme, banyo sırasında lif, banyo sonrasında nemlendirici kullanma, yatağı/beşiği kilitli tutma; eğitimi veren meslek üyesi ile hastane dışından dönüldüğünde, idrar/gaitada kan görüldüğünde yapılanlar, banyo sonrası nemlendirici kullanma; eğitimin tekrarı ile ağız bakımında kullanılan malzeme, günlük ağız bakımı yapma sıklığı, yatağı/beşiği kilitli tutma, maske kullanma, sebze/meyvelerin temizlik şekli, oyuncak seçimi, diş fırçalamaya izin verme, lif kullanma, idrar/gaitada kan görüldüğünde yapılanlar, banyo sonrası nemlendirici kullanma arasındaki fark anlamlıdır $(p<0,05)$.

Sonuç: Eğitimlerin özel bir hemşire tarafından verilmesi istenmektedir. Eğitimin zamanı, tekrarı, eğitimi veren meslek üyesi eğitimin etkinliğini etkilemektedir.

Anahtar kelimeler: Bakım verici, çocuk, eğitim, kemoterapi, uygulama

\begin{abstract}
Training and Practice Characteristics of Caregivers of Children Receiving Chemotherapy Treatment for Treatment-Related Complications

Aim: This cross-sectional research was conducted with the purpose of determining the training and practice characteristics of caregivers of children receiving chemotherapy treatment for treatment-related complications.

Material and Methods: The caregiver of 200 children who received chemotherapy treatment constituted the sample of the study. The data were collected with a 67-question data form. For the analysis of the data; number, percentage and Chi-square tests were used. Results: $42.4 \%$ of caregivers stated that they wanted to receive training from a special education nurse. It was found that the differences between the time of training and the material used in oral care, note and report what children eat, using bath puff during the bath, using moisturizer after bath and keeping the bed/cradle locked were significant $(p<0.05)$. There were also significant differences between the professional member who gives the training and the things done when returning to the hospital and blood is seen in urine/stool and using moisturizer after bath $(p<0.05)$. The difference between the repetition of the training and the material used in oral care, the frequency of daily oral care, keeping the bed/cradle locked, using mask, cleaning vegetables/fruits, choosing toys, allowing brushing teeth, using bath puff, the things done when blood is seen in urine/stool and using moisturizer after bathing have been found to be significant $(\mathrm{p}<0.05)$.

Conclusion: Caregivers request the training to be given by a private nurse. The time of the training, the repetition of the training and the professional member who gives the training affect the effectiveness of the training.
\end{abstract}

Keywords: caregiver, chemotherapy, child, education, practice

${ }^{1}$ Doç. Dr. Ankara Yıldırım Beyazıt Üniversitesi Sağlık Bilimleri Fakültesi Hemşirelik Bölümü Ankara, Türkiye, E-mail: sibel_9741@hotmail.com, Tel: +90 3129061000 / 1932, ORCID: 0000-0001-9009-1871

${ }^{2}$ Bilim Uzmanı, Hemşire, Ankara Şehir Hastanesi, Yanık Ünitesi, Ankara, Türkiye, E-mail: zey_tun24@windowslive.com, Tel: 0538 355 45 52, ORCID: 0000-0003-2595-2537 ${ }^{3}$ Bilim Uzmanı, Hemşire, Arif Göçmen Aile Sağlığı Merkezi, Ankara, Türkiye, E-mail: seldaishik@hotmail.com, Tel: 0541 484 05 58, ORCID: 0000-0002-4220-543X Geliş Tarihi: 4 Temmuz 2018, Kabul Tarihi: 3 Mart 2020

Atıf/Citation: Küçük S, Uzun Z, Işık Eyyuplu S. Kemoterapi Tedavisi Alan Çocukların Bakım Vericilerinin Tedaviye Bağlı Komplikasyonlara Yönelik Eğitim Alma ve Uygulama Özellikleri. Hacettepe Üniversitesi Hemşirelik Fakültesi Dergisi 2020; 7(2): 87-94. DOI: 10.31125/hunhemsire.763126 


\section{GíRiş}

Son yıllarda görülme sıklığı artan kanser vakalarının tedavisinde yaygın olarak kullanılan yöntemlerden olan kemoterapi tedavisi, pek çok yan etki ve soruna yol açabilmektedir ${ }^{1}$. Kemoterapinin yan etkilerine bağlı ortaya çıkan sorunlar çocuğun yaşam kalitesini azaltmanın yanı sıra tedavi sürecini uzatarak sağlık çalışanların iş yüklerini arttırmaktadır ${ }^{2-4}$. Bu olumsuzlukları en aza indirebilmek için kanser tedavisinde hemşire ve diğer sağıık üyelerinin disiplinler arası işbirliği yaklaşımı önerilmekte ve tedavi sürecinde çocuğun bakımından sorumlu bakım vericilerin önemi üzerinde durulmaktadı22,5-8. Bakım vericilerin çocuğun bakımından birinci derecede sorumlu olmaları nedeniyle kemoterapi tedavisinin yan etkilerinin önlenmesi, saptanması ve kontrolünde konularında eğitim almaları gerektiği bildirilmektedir ${ }^{7}$. Kristen ve arkadaşları pediatrik onkolojide aile merkezli bakımın önemi vurgulanmakta ${ }^{5}$ ve çocuğa bakım veren ebeveyn veya bakım verenin de semptom belirlemesi ve kontrolünde yer alması gerektiği vurgulanmaktadır ${ }^{9}$. Kemoterapi tedavisi alan çocuklarda görülebilecek semptom ve yan etkilerin etkin ve bilinçli hemşirelik girişimleri ve bakım vericilerin eğitilmeleri ile önlenebildiği ya da azaltılabildiği belirtilmektedir ${ }^{2,6,9,10}$. Buna karşın onkoloji alanında hasta ve bakım vericilerine hemşire ve diğer sağlık çalışanları tarafından kemoterapi yan etkileri konusunda yapılan bilgilendirmelerin hasta gereksinimlerini yeterince karşılamadığı bildirilmektedir7,11.

Hemşirelerin kanser hastaları ve ailelerini, gereksinimleri doğrultusunda bilgilendirmesi, profesyonel destek sağlaması, semptom yönetimine ve kendi bakımlarına yönelik düzenli olarak eğitim ve danışmanlık yapmasının önemli olduğu ve pediatrik onkoloji hemşiresinin en önemli rollerinden birinin eğitim ve danışmanlık rolü olduğu belirtilmektedir ${ }^{2,12}$.

\section{Araştırmanın Amacı}

Araştırma kemoterapi tedavisi alan çocukların bakım vericilerinin tedaviye bağlı komplikasyonlara yönelik eğitim alma ve uygulama özelliklerinin incelenmesi amacıyla yapılmıştır.

\section{GEREÇ ve YÖNTEM}

\section{Araştırmanın Türü}

Araştırma tanımlayıcı kesitsel tipte yapıımıştır.

Araştırmanın Evreni ve Örneklemi

Araştırmanın evrenini Ankara il merkezinde bulunan bir çocuk hematoloji onkoloji hastanesinde kemoterapi tedavisi için hematoloji ve hematoloji-onkoloji ünitelerinde yatan 248 çocuğun bakım vericisi oluşturmuştur. Herhangi bir örneklem seçimine gidilmemiş, araştırmaya katılmayı kabul eden, iletişim engeli bulunmayan ve Türkçe konuşan 200 bakım verici araştırmanın örneklemini oluşturmuştur.

\section{Verilerin Toplanmas}

Veriler 15.03.2014-15.03.2015 tarihleri arasında araştırmacılar tarafından oluşturulan veri toplama formu ile toplanmıştır. Veri toplama formu iki bölümden oluşmuştur. Birinci bölümde bakım vericilerin ve çocukların sosyodemografik ve hastalık özelliklerini sorgulayan 18 soru yer almaktadır. İkinci bölüm ise kemoterapiye ilişkin oluşabilecek sorunlara yönelik uygulamaları sorgulayan 8 , ağız bakımı ile ilgili 10, enfeksiyon riski ile ilgili 14 soru, beslenmeye ile ilgili 6 soru ve kanama riski ile ilgili 11 soru olmak üzere toplam 67 kapalı uçlu sorudan oluşmuştur. Veriler araştırmacılar tarafından yüz yüze görüşme yöntemi ile toplanmıştır.

\section{Verilerin Değerlendirilmesi}

Değerlendirmede sayı, yüzde, Ki kare test istatistikleri kullanılmıştır. Anlamlılık değeri $p<0.05$ kabul edilmiştir (IBM SPSS Statistics 21.0 (IBM Corp. Released 2012. IBM SPSS Statistics for Windows Version 21.0. Amornk, NY: IBM Corp.).

\section{Araştırmanın Etik Boyutu}

Araştırmaya başlanmadan önce gerekli etik izin (Ankara Çocuk Sağlığı ve Hastalıkları Hematoloji Onkoloji EAH:2014/010) alınmıştır. Bakım vericilerinden gönüllü araştırma onam formu ile onam alınmıştır.

\section{BULGULAR}

Araştırmaya katılan bakım vericilerin çoğunluğunun 26-36 (\%41.5) ve 18-25 (\%29.0) yaş grubunda yer aldığı, tamamının kadın, \%86.0'sının ev hanımı, \%47.0'sinin okuryazar/ilkokul mezunu, \%97.0'sinin çocuğun annesi olduğu ve \%76.5'inin maddi durumunu orta olarak tanımladığı belirlenmiştir. Kemoterapi alan çocukların yaşlarının 0-5 arasında (\%53.0) yoğunlaştığı, \%51.0'nin cinsiyetinin kız olduğu, \%36.5'inin Akut Lenfoblastik Lösemi (ALL), \%22.5'nin Akut Miyeloid Lösemi (AML) tanısı aldığı, \%91.5'inin kemoterapi, \%5.0'inin radyoterapi, \%3.5'inin Kemik iliği Transplantasyonu (KIT) tedavisi, \%95.5'inin halen kemoterapi tedavisi aldığı saptanmıştır. Kemoterapi tedavisi sırasında çocukların \%41.0'inin ağız yarası, \%15.5'inin kan değerlerinde düşme, \%34.5'inin bulantı, kusma, iştahsızlık, kabızlık, ishal gibi Gis problemleri, \%9.0'unun halsizlik ve anksiyete problemi yaşadığı belirlenmiştir (Tablo 1 ).

Tablo 1. Bakım Vericilerin ve Çocukların Sosyodemografik ve Kemoterapi Tedavisine Ait Özellikleri $(n=200)$

\begin{tabular}{|l|c|c|}
\hline Özellikler & $\mathbf{n}$ & $\mathbf{\%}$ \\
\hline Bakım vericiye ait özellikler & & \\
\hline Cinsiyet & & \\
\hline Kadın & 200 & 100 \\
\hline Yaş & & \\
\hline $18-25$ & 58 & 29.0 \\
\hline $26-35$ & 83 & 41.5 \\
\hline $36-45$ & 47 & 23.5 \\
\hline 45 ve üzeri & 12 & 6.0 \\
\hline Eğitim durumu & & \\
\hline Okuryazar/ilkokul & 94 & 47.0 \\
\hline Ortaokul & 51 & 25.5 \\
\hline Lise & 49 & 24.5 \\
\hline Üniversite & 6 & 3.0 \\
\hline
\end{tabular}


Tablo 1. Bakım Vericilerin ve Çocukların Sosyodemografik ve Kemoterapi Tedavisine Ait Özellikleri ( $n=200)$ (devamı)

\begin{tabular}{|c|c|c|}
\hline Çalışma durumu & & \\
\hline Ev hanımı & 172 & 86.0 \\
\hline Çalışıyor & 28 & 14.0 \\
\hline \multicolumn{3}{|l|}{ Çocuğa yakınlığı } \\
\hline Anne & 194 & 97.0 \\
\hline Diğer* & 6 & 3.0 \\
\hline \multicolumn{3}{|l|}{ Algılanan maddi durum } \\
\hline İyi & 42 & 21.0 \\
\hline Orta & 153 & 76.5 \\
\hline Kötü & 5 & 2.5 \\
\hline \multicolumn{3}{|l|}{ Çocuğa ait özellikler } \\
\hline \multicolumn{3}{|l|}{ Cinsiyet } \\
\hline $\mathrm{KIz}$ & 102 & 51.0 \\
\hline Erkek & 98 & 49.0 \\
\hline \multicolumn{3}{|l|}{ Yaş } \\
\hline $0-5$ & 106 & 53.0 \\
\hline $6-10$ & 65 & 32.5 \\
\hline $11-18$ & 29 & 14.5 \\
\hline \multicolumn{3}{|l|}{ Tanı } \\
\hline ALL & 73 & 36.5 \\
\hline AML & 45 & 22.5 \\
\hline Diğer onkolojik hastalıklar** & 43 & 21.5 \\
\hline Diğer hematolojik hastalıklar*** & 39 & 19.5 \\
\hline \multicolumn{3}{|l|}{ Daha önce aldığı tedavi } \\
\hline Kemoterapi & 183 & 91.5 \\
\hline Radyoterapi & 10 & 5.0 \\
\hline Кіт & 7 & 3.5 \\
\hline \multicolumn{3}{|l|}{$\begin{array}{l}\text { Halen kemoterapi tedavisi alma } \\
\text { durumu }\end{array}$} \\
\hline Alıyor & 191 & 95.5 \\
\hline Almıyor & 9 & 4.5 \\
\hline \multicolumn{3}{|l|}{$\begin{array}{l}\text { Kemoterapi tedavi } \text { sırasında } \\
\text { karşılaşılan problemler***** }\end{array}$} \\
\hline Ağız yarası oluşma & 82 & 41.0 \\
\hline $\begin{array}{l}\text { GiS problemleri (Bulantı, kusma, } \\
\text { iștahsızlık, ishal, kabızlık) }\end{array}$ & 56 & 34.5 \\
\hline Kan değerlerinde düşme & 31 & 15.5 \\
\hline Huzursuzluk, anksiyete & 18 & 9.0 \\
\hline Halsizlik & 18 & 9.0 \\
\hline
\end{tabular}

*Abla, hala, teyze, babaanne

** Kronik Myeloid Lösemi (KML), aplastik anemi, hemofagositik

lenfohistiyositoz (HLH), lenfoma

*** Radyosarkom, osteosarkom, Ewing sarkom

****Soruya birden fazla yanıt verilmiştir. Yüzdeler $\mathrm{n}$ sayısı üzerinden değerlendirilmiştir.

Bakım vericilerin tamamının kemoterapi yan etkilerine yönelik olarak eğitim aldığı, \%96.0'sının tüm eğitim konularında, \%29.0'unun hastaneye yatışın 2. günü, \%92.5'inin sözel olarak, \%50.0'sinin ise hemşirelerden eğitimleri aldığı saptanmıştır. \%93.5' $\mathrm{i}$ eğitimin tekrarlandığını, \%84.5'ü eğitimleri yararlı bulduğunu, \%42.4'ü eğitimlerin bir eğitim hemşiresi tarafından verilmesini istediğini belirtmiştir (Tablo 2).
Tablo 2. Kemoterapi Yan Etkilerine Yönelik Alınan Eğitim ile İgili Değişkenler $(\mathrm{n}=\mathbf{2 0 0})$

\begin{tabular}{|l|c|c|}
\hline Değişkenler & $\mathbf{n}$ & $\mathbf{\%}$ \\
\hline Eğitim alma durumu & 200 & 100 \\
\hline Eğitim konuları & & \\
\hline Enfeksiyon riski & 6 & 3.0 \\
\hline Ağız bakımı & 1 & 0.5 \\
\hline Beslenme & 1 & 0.5 \\
\hline Hepsi & 192 & 96.0 \\
\hline Eğitim alma zamanı & & \\
\hline Hastaneye yatışın ilk günü & 62 & 31.0 \\
\hline Hastaneye yatışın 2. günü & 58 & 29.0 \\
\hline Hastaneye yatı̧ın 3-7. günü & 45 & 22.5 \\
\hline $\begin{array}{l}\text { Hastaneye yatıştan sonraki bir } \\
\text { haftadan sonra }\end{array}$ & 35 & 17.5 \\
\hline Eğitim şekli & & \\
\hline Sözel & 185 & 92.5 \\
\hline Yazııı materyal kullanılarak & 5 & 2.5 \\
\hline Sözel ve yazııı materyal kullanılarak & 10 & 5.0 \\
\hline Eğitimi veren kişi & & \\
\hline Hemşire & 100 & 50.0 \\
\hline Hekim & 35 & 17.5 \\
\hline Hemşire-hekim birlikte & 65 & 32.5 \\
\hline Tekrarlı eğitim alma durumu & 187 & 93.5 \\
\hline $\begin{array}{l}\text { Eğitimin yararlı olduğunu düşünme } \\
\text { durumu }\end{array}$ & & \\
\hline \begin{tabular}{l} 
Çok yararlı \\
\hline Yararlı
\end{tabular} & 169 & 84.5 \\
\hline Yararlı değil & 27 & 13.5 \\
\hline Eğitime yönelik öneriler (n=170) & 4 & 1.5 \\
\hline Eğitim hemşiresi tarafından verilmesi & 72 & 42.4 \\
\hline $\begin{array}{l}\text { Eğitim için kitap ve broşür } \\
\text { hazırlanması }\end{array}$ & 51 & 30.0 \\
\hline Daha ayrıntııı bilgi verilmesi & 32 & 18.8 \\
\hline Ilk gün eğitim verilmemesi & 12 & 7.1 \\
\hline Daha sı eğitim verilmesi & 3 & 1.8 \\
\hline & & \\
\hline
\end{tabular}

Bakım vericilerin \%70.5'i ağız bakımında "sodyum bikarbonat+gargara+fungostatin" kullandığını, \%35.0'i her yemekten sonra ağız bakımı yaptığını belirtmiştir. Bakım vericilerin \%91.0'inin çocuğun yanında maske kullandığı, \%94.0'ünün odayı sık sık havalandırdığı, \%28.0'inin çocuğunu haftada bir banyo yaptırdığı, \%22.0'sinin çocuğun kıyafetlerini ütülediği, \%99.0'unun sık sık ellerini yıkadığı, \%56.5'inin hastane dışından döndüğünde sadece elini yıkadığı, \%97.5'inin çocuğun kişisel eşyalarını ayırdığı belirlenmiş ve \%93.0'ü çocuğun oyuncaklarının yıkanabilen özellikte olduğunu belirtmiştir. Bakım vericilerin \%41.0'i çocuk isterse dışardan yemek aldığını, \%77.0'si çocuğun yediklerini not ettiğini, tamamı (\%100) yemek yemeyi etkileyen faktörleri hekim ve hemşireye bildirdiğini, \%90.0'ı sebze ve meyveleri çocuğuna yedirmeden önce sirkeli suda bekletip yıkadığını ifade etmiştir. Bakım vericilerden çocuğun vücudunda kızarıklık/morluk olduğunda hekim ve hemşireye bildirdiğini, defekasyonu ve anal bölgeyi günlük takip ettiğini, yatak/beşiği kilitli tuttuğunu söyleyenlerin oranın yüksek olduğu (\%90) ve bakım vericilerin yalnızca \%28.0'inin çocuğun banyosu sırasında lif kullanmaya izin verdiği ve yine bakım vericilerin \%13.5'ünün tırnak vb. kesmeden önce trombosit değerini kontrol ettiği belirlenmiştir (Tablo 3). 
Tablo 3. Bakım Vericilerin Tedavinin Yan Etkilerini Önlemeye Yönelik Uygulamaları $(\mathrm{n}=\mathbf{2 0 0})$

\begin{tabular}{|c|c|c|}
\hline Ağız Bakımı & $\mathbf{n}$ & $\%$ \\
\hline \multicolumn{3}{|l|}{ Ağız bakımında kullanılan malzeme } \\
\hline Sodyum bikarbonat & 17 & 8.5 \\
\hline Sodyum bikarbonat+gargara & 42 & 21.0 \\
\hline Sodyum bikarbonat+gargara+fungostatin & 141 & 70.5 \\
\hline \multicolumn{3}{|l|}{ Günlük ağız bakımı yapma sıklığı } \\
\hline $1 \mathrm{kez}$ & 41 & 20.5 \\
\hline $2 \mathrm{kez}$ & 57 & 28.5 \\
\hline Her yemek sonrası & 70 & 35.0 \\
\hline Her yemek sonrası+yatmadan önce & 32 & 16.0 \\
\hline \multicolumn{3}{|l|}{ Enfeksiyon } \\
\hline Maske kullanma & 182 & 91.0 \\
\hline Odayı sık havalandırma & 188 & 94.0 \\
\hline \multicolumn{3}{|l|}{ Banyo yaptırma sıklığı } \\
\hline Her gün & 47 & 23.5 \\
\hline Gün aşırı & 53 & 26.5 \\
\hline Haftada bir & 56 & 28.0 \\
\hline Gerektikçe & 44 & 22.0 \\
\hline Kıyafetleri ütüleme & 105 & 52.5 \\
\hline \multicolumn{3}{|l|}{ El yıkama sıklığı } \\
\hline SIk sık & 198 & 99.0 \\
\hline Kirlenince & 2 & 1.0 \\
\hline \multicolumn{3}{|l|}{$\begin{array}{l}\text { Hastane dışından geldikten sonra yapılan } \\
\text { uygulamalar }\end{array}$} \\
\hline El yıkama & 113 & 56.5 \\
\hline Banyo + kıyafet değiştirme & 87 & 43.5 \\
\hline Çocuğun kişisel eşyalarının ayırma & 195 & 97.5 \\
\hline \multicolumn{3}{|l|}{$\begin{array}{l}\text { Çocuğa oyuncak seçerken dikkat edilen } \\
\text { özellikler }\end{array}$} \\
\hline Yıkanabilme & 186 & 93.0 \\
\hline Kadife, pelüş içermeme & 14 & 7.0 \\
\hline \multicolumn{3}{|l|}{ Beslenme } \\
\hline Çocuk istediğinde dışarıdan yemek alma & 82 & 41.0 \\
\hline Yediklerini not etme & 154 & 77.0 \\
\hline Yemek yemeyi etkileyen faktörleri bildirme & 200 & 100.0 \\
\hline \multicolumn{3}{|l|}{ Sebze/meyvelerin temizlik şekli } \\
\hline Yıkamama/sadece su ile yıkama & 20 & 10.0 \\
\hline Sirkeli suda bekletip yıkama & 180 & 90.0 \\
\hline \multicolumn{3}{|l|}{ Kanama riski } \\
\hline $\begin{array}{ll}\text { Vücutta kızarıklık, morluk olduğunda } \\
\text { bildirme }\end{array}$ & 199 & 99.5 \\
\hline Günlük defekasyonu takip etme & 198 & 99.0 \\
\hline Anal bölgeyi günlük gözlemleme & 192 & 96.0 \\
\hline Yatağı/beşiği kilitli tutma & 180 & 90.0 \\
\hline Banyo sonrası nemlendirici kullanma & 170 & 85.0 \\
\hline Diş fırçası kullanmama & 164 & 82.0 \\
\hline Banyo sırasında lif kullanma & 56 & 28.0 \\
\hline $\begin{array}{l}\text { Tırnak kesmeden önce trombosit değerini } \\
\text { kontrol etme }\end{array}$ & 27 & 13.5 \\
\hline
\end{tabular}

Eğitimin verilme zamanı ile çocuğu kemoterapi tedavisi alınırken ağız bakımında kullanılan malzeme, günlük ağız bakımı yapma sıklığı, çocuğun yediklerini not etme ve bildirme, banyo sırasında lif, sonrasında nemlendirici kullanma; eğitimi veren meslek üyeleri ile hastane dışından dönüldüğünde ve idrar/gaitada kan görüldüğünde yapılanlar ve banyo sonrası nemlendirici kullanma; eğitimin tekrarı ile ağız bakımında kullanılan malzeme, maske kullanma, sebze/meyvelerin temizlik şekli, oyuncak seçimi, diş fırçalamaya izin verme, lif kullanma, idrar/gaitada kan görüldüğünde yapılanlar ve banyo sonrası nemlendirici kullanma arasında istatistiksel olarak anlamlı fark olduğu belirlenmiştir $(p<0.05)$ (Tablo 4). Tabloda yer almamakla birlikte anal bölgeyi gözlemleme ve eğitimin tekrarı arasında istatistiksel olarak anlamlı fark varken $\left(X^{2}=43.000 ; p<0.001\right)$, kişisel eşyaları ayırma, dışardan yiyecek alma, morluk/kızarıkı görünce bildirme, kıyafetleri ütüleme, banyo yapma zamanı, tırnaklarını kesmeden önce trombosit değerini öğrenme ile eğitimin verilme zamanı, eğitimi veren meslek üyeleri ve eğitimin tekrarı arasında ise istatistiksel olarak anlamlı bir farklılık saptanmamıştır ( $p>0.05)$.

\section{TARTIŞMA}

Kanser tedavisi sırasında bakım vericilerinin kemoterapi tedavisinin yan etkileri ve bu yan etkilerin nasıl önleneceği konularında çoğunlukla hemşirelerden düzenli eğitimler almak istedikleri belirtilmektedir ${ }^{13}$. Bu araştırmada bakım vericilerin tamamının eğitim aldığı ve eğitimlerin genellikle hastaneye yatışın ilk ve ikinci gününde ve sözel olarak verildiği saptanmıştır. Eğitim sırasında yazılı ve görsel materyal kullanımı çok düşüktür (Tablo 2). Bu durumun bakım vericiler açısından eğitimin tekrarı ve kalıcılığı bakımından önemli bir eksiklik olduğu düşünülmüştür. Verilen eğitimleri bakım vericilerin büyük çoğunluğu yararlı bulmaktadır. Bakım vericilerin eğitimlerin özel bir hemşire tarafından ve kitap ve broşür kullanılarak verilmesini istemeleri dikkat çekicidir (Tablo 2). Hastaneye yatışın ilk günü eğitim verilememesini isteyen bakım vericiler bulunmasında bakım vericiler ve çocuklarda ilk gün oluşabilecek stresin etkili olduğu düşünülmüştür.

Kemoterapi tedavisinin en sık yan etkilerinden olan mukozit ve ağız yarası gelişmesi litaretüre uygun olarak ${ }^{14,15}$ bu çalışmada da yüksektir (Tablo 3). Mukozite bağlı ağız koplikasyonlarının önlenmesi için ağız bakımının iyi yapılması gerektiği bildirilmektedir ${ }^{16}$. Bakım vericilerin büyük çoğunluğu tedavi gördükleri hastane protokolünde yer aldığı şekilde ağız bakımını yapmaktadır. Araştırmanın yapıldığı hastanede sodyum bikarbonat, gargara ve fungostatin ağız bakımında kullanılan temel ajanlardır ve bu ajanların birlikte kullanımı yüksektir (Tablo 3). Ancak bakım vericilerin yalnızca $\% 16^{\prime}$ sı ağız bakımını olması gereken zamanda yapmaktadır.

Ağız bakımı ile ilgili eğitimlerin alınma zamanı ve eğitimin tekrarı ağız bakımında kullanılan malzemeleri, tek başına eğitimin tekrarı ise ağız bakımı yapma sıklığını etkilemiştir $(p<0.05)$. Hastaneye yatışın ilk haftasında ve daha sonra eğitimleri tekrar alan bakım vericiler daha yüksek oranda sodyum bikarbonat +gargara+fungostatin'li gargara kullanarak, en az günde bir defa ve her yemekten sonra ve yatmadan önce çocuklarına ağız bakımı yapmışladır (Tablo 4). Ağız bakımında uygun solüsyon kullanılması ve ağız bakım sıklı̆ının istendik düzeyde olmasının kemoterapinin sık görülen yan etkilerinden biri olan ağız yarası görülme oranlarını azaltabileceği düşünülmüştür. Ayrıca bir kez ağız bakımı yapan ebeveynlerin tamamının eğitimleri tekrarlı alan bakım vericilerden oluşması dikkat çekmiştir. 
Tablo 4. Bakım Vericilerin Ağız Bakımı, Enfeksiyon, Beslenme ve Kanam Riskine Yönelik Uygulamalarının Eğitimin Zamanı, Eğitimi Veren Sağılk Personeli ve Eğitimin Tekrar Edilme Durumuna Göre Karşılaştırılması (n=200)

\begin{tabular}{|c|c|c|c|c|c|c|c|c|c|c|c|c|}
\hline \multirow{3}{*}{ Değişkenler } & \multicolumn{4}{|c|}{ Eğitim zamanı } & \multicolumn{4}{|c|}{ Eğitimi veren sağlık personeli } & \multicolumn{4}{|c|}{ Eğitimin tekrarı } \\
\hline & \multicolumn{2}{|c|}{$\begin{array}{c}\text { Hastaneye yatışın ilk } \\
\text { haftasında }\end{array}$} & \multicolumn{2}{|c|}{$\begin{array}{l}\text { Hastaneye yatışın ilk } \\
\text { haftasından sonra }\end{array}$} & \multicolumn{2}{|c|}{ Hemşire } & \multicolumn{2}{|c|}{ Hekim } & \multicolumn{2}{|c|}{ Evet } & \multicolumn{2}{|c|}{ Hayır } \\
\hline & $\mathbf{n}$ & $\%$ & $\mathbf{n}$ & $\%$ & $\mathbf{n}$ & $\%$ & $\mathbf{n}$ & $\%$ & $\mathbf{n}$ & $\%$ & $\mathbf{n}$ & $\%$ \\
\hline \multicolumn{13}{|l|}{ Ağız Bakımı } \\
\hline \multicolumn{13}{|l|}{ Ağız bakımında kullanılan malzeme } \\
\hline Sodyum bikarbonat & 15 & 88.2 & 2 & 11.8 & 12 & 70.6 & 5 & 29.4 & 12 & 70.6 & 5 & 29.4 \\
\hline Sodyum bikarbonat +gargara & 27 & 64.3 & 15 & 35.7 & 26 & 85.7 & 6 & 14.3 & 41 & 97.6 & 1 & 2.4 \\
\hline $\begin{array}{l}\text { Sodyum bikarbonat } \\
\text { +gargara+fungostatin }\end{array}$ & 123 & 87.2 & 18 & 12.8 & 117 & 83.0 & 24 & 17.0 & 134 & 93.5 & 7 & 6.5 \\
\hline Analiz & \multicolumn{4}{|c|}{$X^{2}: 12.227 ; p: 0.002$} & \multicolumn{4}{|c|}{$\mathrm{X}^{2}: 1.994 ; \mathrm{p}: 0.50$} & \multicolumn{4}{|c|}{$X^{2}: 16.403 ; p<0.001$} \\
\hline \multicolumn{13}{|l|}{ Günlük ağız bakımı yapma sıklığı } \\
\hline $1 \mathrm{kez}$ & 28 & 68.3 & 13 & 31.7 & 40 & 97.6 & 1 & 2.4 & 41 & 100 & 0 & 0.0 \\
\hline $2 \mathrm{kez}$ & 49 & 86.0 & 8 & 14.0 & 47 & 82.5 & 10 & 17.5 & 52 & 91.2 & 5 & 8.8 \\
\hline Her yemek sonrası & 59 & 84.3 & 11 & 15.7 & 56 & 80.0 & 14 & 20.0 & 62 & 88.6 & 8 & 11.4 \\
\hline Her yemek sonrası +yatmadan önce & 29 & 90.6 & 3 & 9.4 & 22 & 68.8 & 10 & 31.2 & 32 & 100 & 0 & 0.0 \\
\hline Analiz & \multicolumn{4}{|c|}{$X^{2}: 7.824 ; p: 0.50$} & \multicolumn{4}{|c|}{$X^{2}: 10.935 ; p: 0.369$} & \multicolumn{4}{|c|}{$X^{2}: 8.357 ; p: 0.039$} \\
\hline \multicolumn{13}{|l|}{ Enfeksiyon Riski } \\
\hline \multicolumn{13}{|l|}{ Maske kullanma } \\
\hline Evet & 148 & 89.7 & 34 & 97.1 & 90 & 90.0 & 32 & 92.4 & 175 & 93.6 & 7 & 53.8 \\
\hline Hayır & 17 & 103 & 1 & 2.9 & 10 & 10.0 & 3 & 8.6 & 12 & 6.4 & 6 & 46.2 \\
\hline Analiz & \multicolumn{4}{|c|}{$\mathrm{X}^{2}: 1955 ; \mathrm{p}: 0.162$} & \multicolumn{4}{|c|}{$\mathrm{X}^{2}: 0.266 ; \mathrm{p}: 0.876$} & \multicolumn{4}{|c|}{$X^{2}: 23.434 ; p<0.001$} \\
\hline Hastane dışından dönüldüğünde ya & & & & & & & & & & & & \\
\hline Sadece el yıkama & 97 & 58.8 & 16 & 45.7 & 86 & 52.1 & 27 & 77.1 & 105 & 56.1 & 8 & 61.5 \\
\hline Banyo yapma, kıyafet değiştirme & 68 & 41.2 & 19 & 54.3 & 79 & 47.9 & 8 & 22.9 & 82 & 43.9 & 5 & 38.5 \\
\hline Analiz & & $X^{2}: 1$ & 0.219 & & $X^{2}: 17.43$ & .007 & & & & $\mathrm{X}^{2}: 0.14$ & 0.705 & \\
\hline Oyuncak seçiminde dikkat edilenler & & & & & & & & & & & & \\
\hline Yıkanabilen & 151 & 91.5 & 35 & 100 & 153 & 92.7 & 33 & 94.3 & 176 & 94.1 & 10 & 76.9 \\
\hline Kadife/pelüş içermeyen & 14 & 8.5 & 0 & 0.0 & 12 & 7.3 & 2 & 5.7 & 11 & 5.9 & 3 & 23.1 \\
\hline Analiz & & $x^{2}: 3$ & 0.07 & & $x^{2}: 0.108$ & 743 & & & & $x^{2}: 5.52$ & 0.019 & \\
\hline Beslenme & & & & & & & & & & & & \\
\hline Yediklerini not etme, yemek yemey & en faktc & dirme & & & & & & & & & & \\
\hline Evet & 136 & 82.4 & 18 & 51.4 & 127 & 77.0 & 27 & 77.1 & 146 & 78.1 & 8 & 61.5 \\
\hline Hayır & 29 & 17.6 & 17 & 48.6 & 38 & 23.0 & 8 & 22.9 & 41 & 21.9 & 5 & 38.5 \\
\hline Analiz & & $X^{2}: 15$ & $<0.001$ & & $x^{2}: .000$ & & & & & $X^{2}: 1.87$ & 0.171 & \\
\hline Sebze/meyve temizlik şekli & & & & & & & & & & & & \\
\hline $\begin{array}{l}\text { Sadece su } \\
\text { ile yıkama }\end{array}$ & 19 & 11.5 & 1 & 2.9 & 15 & 9.1 & 5 & 14.3 & 13 & 7.0 & 7 & 53.8 \\
\hline $\begin{array}{l}\text { Sirkeli su ile yıkama/ } \\
\text { Bekletme }\end{array}$ & 146 & 88.5 & 34 & 97.1 & 150 & 90.9 & 30 & 85.7 & 174 & 93.0 & 6 & 46.2 \\
\hline Analiz & & $X^{2}: 2$ & 0.121 & & $X^{2}: 0.80 €$ & & & & & $2: 29.70$ & $<0.00$ & \\
\hline
\end{tabular}


Tablo 4. Bakım Vericilerin Ağız Bakımı, Enfeksiyon, Beslenme ve Kanam Riskine Yönelik Uygulamalarının Eğitimin Zamanı, Eğitimi Veren Sağık Personeli ve Eğitimin Tekrar Edilme Durumuna Göre Karşılaştırııması ( $n=200)$ (devamı)

\begin{tabular}{|c|c|c|c|c|c|c|c|c|c|c|c|c|}
\hline \multicolumn{13}{|l|}{ Kanama Riski } \\
\hline \multicolumn{13}{|c|}{ Diş fırçası kullanmama } \\
\hline Evet & 132 & 80.5 & 32 & 91.4 & 137 & 83.5 & 27 & 77.1 & 157 & 84.0 & 7 & 58.3 \\
\hline Hayır & 32 & 19.5 & 3 & 8.6 & 27 & 16.5 & 8 & 22.9 & 30 & 16.0 & 5 & 41.7 \\
\hline Analiz & \multicolumn{4}{|c|}{$\mathrm{X}^{2}: 2.382 ; \mathrm{p}: 0123$} & \multicolumn{4}{|c|}{$\mathrm{X}^{2}: .814 ; \mathrm{p}: 0.367$} & \multicolumn{4}{|c|}{$X^{2}: 5.108 ; \mathbf{p}: 0.024$} \\
\hline \multicolumn{13}{|c|}{ Banyo sırasında lif kullanma } \\
\hline Evet & 53 & 32.1 & 3 & 8.6 & 47 & 28.5 & 9 & 25.7 & 47 & 25.1 & 9 & 69.2 \\
\hline Hayır & 112 & 67.9 & 32 & 91.4 & 118 & 71.4 & 26 & 74.3 & 140 & 74.9 & 4 & 30.8 \\
\hline Analiz & \multicolumn{4}{|c|}{$X^{2}: 7.943 ; \mathbf{p}: 0.005$} & \multicolumn{4}{|c|}{$X^{2}: 0.110 ; p: 0.740$} & \multicolumn{4}{|c|}{$X^{2}: 11.724 ; \mathbf{p}: 0.001$} \\
\hline \multicolumn{13}{|c|}{ İdrar/gaitada kan gördüğünde yapılanlar } \\
\hline Geçmesini bekleme & 1 & 0.6 & 0 & 0.0 & 0 & 0.0 & 1 & 2.9 & 0 & 0.0 & 1 & 7.7 \\
\hline Bildirme & 164 & 99.4 & 35 & 100 & 165 & 100 & 34 & 97.1 & 187 & 100 & 12 & 92.3 \\
\hline Analiz & \multicolumn{4}{|c|}{ Fisher: $\mathrm{p}: 1.000$} & \multicolumn{4}{|c|}{$X^{2}: 4.738 ; p: 0.030$} & \multicolumn{4}{|c|}{$X^{2}: 14.457 ; p<0.001$} \\
\hline \multicolumn{13}{|c|}{ Yatağı/beşiği kilitli tutma } \\
\hline Evet & 145 & 80.6 & 35 & 19.4 & 147 & 81.7 & 33 & 18.3 & 171 & 95.0 & 9 & 5.0 \\
\hline Hayır & 20 & 100.0 & 0 & 0.0 & 18 & 90.0 & 2 & 10.0 & 16 & 80.0 & 4 & 20.0 \\
\hline Analiz & \multicolumn{4}{|c|}{$X^{2}: 4.714 ; \mathbf{p}: \mathbf{0 . 0 3 0}$} & \multicolumn{4}{|c|}{$X^{2}: 0.866 ; p: 0.352$} & \multicolumn{4}{|c|}{$X^{2}: 6.664 ; p: 0.010$} \\
\hline \multicolumn{13}{|c|}{ Banyo sonrası nemlendirici kullanma } \\
\hline Evet & 136 & 82.4 & 34 & 97.1 & 147 & 89.1 & 1 & 65.7 & 163 & 87.2 & 7 & 53.8 \\
\hline Hayır & 29 & 17.6 & 1 & 2.9 & 18 & 10.9 & 12 & 34.3 & 24 & 12.8 & 6 & 46.2 \\
\hline Analiz & \multicolumn{4}{|c|}{$\mathrm{X}^{2}: 4.906 ; \mathbf{p}: \mathbf{0 . 0 2 7}$} & \multicolumn{4}{|c|}{$X^{2}: 12.376 ; p<0.001$} & \multicolumn{4}{|c|}{$X^{2}: 10.508 ; p: 0.001$} \\
\hline
\end{tabular}


Enfeksiyon oranlarını azaltabilmek için nötropenik alanlarda maske kullanımı ${ }^{17,18}$, el hijyenine dikkat edilmesi ${ }^{19}$, oda bulundurulan oyuncakların silinebilir, sağlıklı malzemelerden üretilen, kadife/peluş içermeyen özellikte olması ${ }^{20,21}$ önerilmektedir. Bu araştırmada el yıkama, maske kullanımı, doğru oyuncak seçimi, çocuğun kişisel eşyalarının ayrılması oranlarının yüksek olduğu belirlenmiştir (Tablo 3). Maske kullanımı ve doğru oyuncak seçimi eğitimlerin tekrarıyla anlamlı düzeyde artmaktadır $(p<0.05)$.

Ancak banyo yaptırma rutini, kıyafet ütüleme, hastane dışından dönüşte el yıkama, banyo yapma ve kıyafet değiştirme oranlarının yeterli olmadığı görülmüştür (Tablo 3). Hastane dışından dönüldüğünde yapılması gerekenler konusunda hekimlerden eğitim alanlarda sadece el yıkma oranları yüksek iken banyo yapma ve kıyafetleri değiştirme oranı hemşirelerden eğitim alma ile yükselmektedir ve eğitimi veren meslek mensubu ile anlamlı farklılık oluşmaktadır $(\mathrm{p}<0.05)$ (Tablo 4).

Kanser tedavisi sırasında beslenmenin çocuk hastanın genel durumunu, uygulanan tedavilerin devamlılığını ve bakımın niteliğini etkileyen önemli bir etken olduğu bildirilmektedir $^{16}$. Kemoterapi tedavisi süresince enfeksiyonun önlenmesi için çocukların ev dışında hazırlanan dışarıda satılan besinler yememesinin önemli olduğu ${ }^{22}$ belirtilmesine karşın bakım vericilerin \%41'inin çocuğu istediği takdirde hazır yiyecekler alması olumsuz bir durum olarak değerlendirilmiştir. Nötropenik dönemde pişirilmeyen sebze ve meyvelerin sirkeli suda bekletildikten sonra tüketilmesi önerilmektedir ${ }^{23}$. Ancak bakım vericilerin yalnızca $1 / 10$ 'unun sebze meyveleri hiç yıkamıyor ya da sadece su ile yıkıyor olmaları sağığı olumsuz etkilemesi bakımından önemlidir (Tablo 3).

Çocuğun yediklerini not etme ve yemek yemeyi etkileyen faktörleri bildirme oranı eğitimleri hastaneye yatışın ilk haftasında alan bakım vericilerde yüksektir ve eğitimlerin zamanı ile yediklerini not etme ve yemek yemeyi etkileyen faktörleri bildirme ile eğitim alma zamanı arasında anlamlı fark vardır $(p<0.05)$ (Tablo 4). Eğitimlerin hemşirelerden alınması ise sebze ve meyveleri doğru yıkama tekniğini bilme ile oranlarını anlamlı düzeyde yükselmektedir $(p<0.05)$ (Tablo 4).

Kemoterapi ilaçlarının neden olduğu deri, ağız içi ve anal bölge kanamalarının 24-26. önlenebilmesi amacıyla deri bütünlüğünün korunması ${ }^{24}$, ağız bakımının diş fırçası ile yapılmaması ${ }^{27}$, tırnak kesme gibi yaralanmaya neden olabilecek işlemler öncesinde trombosit değerinin öğrenilmesi28 önerilmektedir. Özellikle düşmeye bağlı oluşabilecek kanamaların önlenmesinde bakım verici olarak annelerin eğitilmesinin önemli olduğu bildirilmektedir ${ }^{29}$. Bu çalışmada bakım vericilerin diğer kanama önlemlerini bilme oranları yüksek iken banyo sırasında lif kullanmama ve tırnak kesmeden önce trombosit değerlerinin kontrol edilmesi gerektiğini bilme oranlarının düşük olduğu görülmüştür (Tablo 3). Eğitimin veriliş zamanı ile banyo sırasında lif kullanma, sonrasında nemlendirici kullanma ve yatağı/beşiği kilitli tutma arasında anlamlı bir fark olması (Tablo 4) eğitimlerin yeteri kadar etkili olmadığını düşündürmüştür. Eğitimleri hemşirelerden alan bakım vericilerin tamamı idrar/gaitada kan gördüğünde bildirmesi ve banyo sonrasında nemlendirici kullanılması gerektiğini bilmektedir. Eğitimlerin tekrarı kanama riskini azaltmak için alınması gereken önlemleri bilmeyi anlamlı olarak etkilemektedir $(p<0.05)$.

\section{SONUÇ ve ÖNERILER}

Bakım vericiler genel hijyen, beslenmeyi etkileyen faktörleri ve kanama riskini bildirme konularında genellikle doğru uygulama yapmaktadır. Bakım vericiler eğitimlerin özel bir hemşire tarafından verilmesini istemektedir. Eğitimleri veren meslek üyesi, eğitimlerin veriliş zamanı ve sıklığı doğru uygulamaları etkilemektedir. Kemoterapi tedavisi alan çocukların bakım vericilerine tedavi yan etkileri konusunda düzenli aralıklarla, uzman bir eğitim hemşiresi tarafından, yazılı ve görsel materyal ile ve uygulamalı olarak eğitim verilmesi önerilebilir.

Etik Kurul Onayı: Ankara Çocuk Sağlığı ve Hastalıkları Hematoloji Onkoloji Eğitim Araştırma Hastanesi Etik Kurulundan alınmıştır (2014/010).

Çıkar Çatışması: Bildirilmemiştir.

Finansal Destek: Yoktur.

Katılımcı Onamı: Bakım vericilerinden bilgilendirilmiş onam alınmıştır.

Yazar katkıları:

Çalışma tasarımı: SK, ZU

Veri toplama ve/veya analizi: SK, ZU, SIE

Makalenin hazırlanması: SK

Teşekkür

Çalışmaya katılan tüm bakım vericilere teşekkür ederiz.

Ethics Committee Approval: Approval was obtained from Ethics Committee of Ankara Child Health and Disease Hematology Oncology Training Researfch Hospital (2014/10).

Confict of Interest: Not reported.

Funding: None.

Exhibitor Consent: Informed consent was obtained from caregivers.

Author contributions:

Study design: SK, ZU

Data collection and analyses: SK, ZU, SIE

Drafting manuscript: SK

Acknowledgement: We would like to thank all caregivers who participated to the study.

\section{KAYNAKLAR}

1. Carelle N, Piotto E, Bellanger A, et al. Changing patient perceptions of the side effects of cancer chemotherapy. Cancer. 2002;95(1):155-63. doi: 10.1002/cncr.10630.

2. Aygül $S$, Ulupınar $S$. Hemşirenin hasta eğitimindeki rolüne yönelik hastaların görüşleri. Anadolu Hemş ve Sağ Bil Derg. 2012;15:1-9.

3. Laugsand EA, Jakobsen G, Kaasa S, et al. Inadequate symptom control in advanced cancer patients across Europe. Sup Care Cancer. 2011;19:2005-2014.

4. Yeşilbalkan Ö, Akyol A, Çetinkaya Y, ve ark. kemoterapi tedavisi alan hastaların tedaviye bağlı yaşadıkları 
semptomlar ve yaşam kalitesine olan etkisinin incelenmesi. EÜ HYO Derg. 2005;21(1):13-31.

5. Kristen E. Holm MS, Joän $M$, et al. Parental involvement and family-centered care in the diagnostic and treatment phases of childhood cancer: Results from a qualitative study. JOPON. 2003;20(6):301-313.

6. Walter W. Rosser JM. Colwill JKasperski, et al. Progress of Ontario's family health team model: a patientcentered medical home. Ann of Fam Med. 2001;9(2): 165-171.

7. Kutlu L, Mutlu L, Kabaoğlu A. Lösemili çocukların ebeveynlerinin bilgilendirilme durumunun değerlendirilmesi. HEAD. 2007;4(1): 32-39.

8. Er M. Çocuk, hastalık, anne-babalar ve kardeşler. Çocuk Sağ ve Hast Derg. 2006;49:155-168.

9. Aslan Ö, Vural H, Kömürcü Ş, ve ark. Kemoterapi alan kanser hastalarına verilen eğitimin kemoterapi semptomlarına etkisi. CÜ HYO Derg. 2006;10(1):1528.

10. Yıldırım N. Kanser hastalarında karşılanmamış gereksinimler. DEÜ HYO Derg. 2013;6(4):231-240.

11. Aranda $S$, Jefford $M$, Yates $P$, et al. Impact of a novel nurse-led prechemotherapy education intervention (ChemoEd) on patient distress, symptom burden, and treatment-related information and support needs: results from a randomised, controlled trial. Ann Oncol. 2012;23(1):222-31.

12. Hollis $R$, The role of the specialist nurse in pediatric oncology in the United Kingdom. EJC. 2005;41(12):1758-1764.

13. Aslan Z, Yiğit R, Temel GÖ. Lösemi hastası çocuk ebeveynlerinin çocuğun bakımına ilişkin eğitim gereksinimlerinin belirlenmesi ve karşılanması. MÜ Sağ Bil Derg. 2014;7(2):58-68.

14. Goldberg S. Patient perceptions about chemotherapyinduced oral mucositis: implications for primary/prophylaxis strategies. Sup Care Cancer. 2004;12:526-30.

15. Bhatt V, Vendrell N, Nau K, et al. Implementation of a standardized protocol for prevention and management of oral mucositis in patients undergoing hematopoietic cell transplantation. J Oncol Pharm Prac. 2010;16:195-204.

16. Kurt A. Çetinkaya Ş. Lösemili çocuklarda yaşam kalitesi ve hemşirelik bakımı. Fırat Sağ Hiz Derg. 2008;3(8):36-56.

17. Hentrich $M$, Schalk E, Schmidt-Hieber M, et al. Central venous catheter-related infections in hematology and oncology: 2012 updated guidelines on diagnosis, management and prevention by the Infectious Diseases Working Party of the German Society of Hematology and Medical Oncology. Ann Oncol. 2014;25(5):936-47.

18. Shang J, Friese $C, W u E$, et al. Nursing Practice environment and outcomes for oncology nursing. Canc Nurs. 2013;36(3):206-212.
19. WHO Guidelines on Hand Hygiene in Health Care. Patient

Safty.http://apps.who.int/iris/bitstream/10665/4410 2/1/9789241597906_eng.pdf

20. Alahan N, Aylaz R, Yetiş G. Kronik hastalığa sahip ebeveynlerin bakım verme yükü. iü Sağ Bil Derg. 2015;4(2):1-5.

21. Aslan F. 1-3 yaş dönemindeki çocuğun oyun ve oyuncak özelliklerinin gelişim kuramları ile açıklanması. CÜ HYO Derg. 2004;4(2):40-43.

22. Başaran G. Kanser hastalarında beslenme. Klinik Gelişim. 2004;17:24-32.

23. Hizel S, Toprak Ş, Albayrak M, ve ark. Kanserli çocuklar hakkında Anadolu'nun kırsal bir ilindeki annelerin bilgi, tutum ve davranışları. Gazi Tıp Derg. 2009;20(1):3-6.

24. American Cancer Society. Cancer Facts \& Figures. How are childhood cancers treated [Internet]. [Erişim Tarihi 29.08.2014.]. Erişim adresi: http://www.cancer.org/cancer/cancerinchildren/det ailedguide/ cancer-in children-treating-how-arechildhood-cancers-treated

25. Karabuğa $H$, Pınar R. Kanserli hastalara bakım veren aile üyelerinin yaşam kalitesi ve yaşam kalitesini etkileyen faktörlerin değerlendirilmesi, HEMAR-G. 2013;15(2):1-16.

26. Zengin O, Saltık $S$, Duysak $Y$, ve ark. Kanserli çocuğa sahip ailelerin aşama yaklaşımına göre gösterdikleri tepkiler, DÜ Sağ Bil Ens Derg. 2012;2(1):1-4.

27. Öztürk $D$, Hintistan $S$. Hastaların dahiliye ve cerrahi kliniklerinde hemşirelerin yaptığı hasta eğitimlerini değerlendirmesi. DEÜ HYO E Derg. 2011;4(4):153.

28. Akçay D, Gözüm S. Kemoterapi alan meme kanserli hastalarda kemoterapinin yan etkilerine ilişkin verilen eğitim ve evde izlemin yaşam kalitesine etkisinin değerlendirilmesi. Meme Sağ Derg. 2012;8(4):191199.

29. Aykanat $B$, Gözen D. Çocuk sağ lığı hemşireliğinde aile merkezli bakım yaklaşımı. GÜ Sağ Bil Derg. 2014;3(1):683-695. 